\title{
Foreign Capital Inflow, Technology Transfer, and National Income
}

\author{
SARBAJIT CHAUDHURI
}

\begin{abstract}
According to Jones and Marjit (1992), in a two-sector, full-employment model it is not possible to show that growth in the foreign capital employed in the export sector of a small open economy will lead to a fall in the welfare in the presence of a protected import-competing sector. In this short paper, we have shown that one may get the immiserising result even in this framework if the inflow of foreign capital into the export sector is accompanied by technology transfer, which leads to a fall in the labour-output ratio in this sector.
\end{abstract}

\section{INTRODUCTION}

The effects of inflow of foreign capital in the developing countries have been investigated intensively by both trade and development theorists. Brecher and Alejandro (1977) have analysed the welfare effects of foreign capital inflow in a two-commodity, two-factor full employment model; and Khan (1982) has considered a mobile capital Harris-Todaro model with urban unemployment. The important result, common to both, is the following: the inflow of foreign capital with full repatriation of its earnings is necessarily immiserising if the import-competing sector is capital-intensive and is protected by a tariff. However, in the absence of any tariff, the foreign capital inflow with full repatriation of its earnings does not affect welfare. Here welfare is defined as a positive function of national income.

In the literature, the Brecher-Alejandro proposition has also been re-examined in terms of the three-sector models. The third sector may either be a duty-free zone (DFZ) (sometimes called foreign enclave), as in the works of Beladi and Marjit (1992, 1992a), or it may be an urban informal sector, as in the works of Grinols (1991), Chandra and Khan (1993), and Gupta (1997). The work of Beladi and Marjit (1992) is a simple three-sector extension of the Heckscher-Ohlin-Samuelson framework, where the third sector, the DFZ, uses sector-specific foreign capital that is foreign-owned. They have shown that with full-repatriation of foreign capital income, growth in the foreign capital can lead to immiserisation in the presence of tariff-distortion even if the foreign capital is employed in the export sector. This

Sarbajit Chaudhuri is based at the Department of Economics, University of Calcutta, Kolkata, India. 
generalises the main result in the existing literature, which primarily focuses on foreign capital movement in the protected sector of the economy.

However, according to Jones and Marjit (1992), in a two-sector, fullemployment model it is impossible to show that growth in the foreign capital employed in the export sector of a small economy will lead to immiserisation. Only a $3 \times 3$ model of trade and production will lead to such a result. The intuition behind the result is as follows. If the inflow of foreign capital to the export sector of the economy increases, it would expand and requires more of the mobile factor. As a consequence, the import-competing sector contracts because of the scarcity of the mobile factor. This raises the national income of the economy at world prices through a decrease in the distortionary effect of tariff protection.

The purpose of the present paper is very simple. I shall show that if the inflow of foreign capital into the export sector of an economy is accompanied by a technology transfer which lowers the labour-output ratio in the export sector, ${ }^{1}$ one may still be able to derive condition under which the immiserising result is obtained in a two commodity-three factor, full-employment model in the presence of a tariffprotected import-competing sector.

\section{THE MODEL}

We consider a $2 \times 3$ specific factor full-employment model. Sector 1 produces the export commodity using labour and capital of type 1 . Sector 2 is the traditional import-competing sector, which produces its output with the help of labour and capital of type 2. By our small open economy assumption the prices of the final commodity are given internationally. However, sector 2 is protected by a tariff, $t$. So its domestic price $P_{2}{ }^{*}$ is different from the world price $P_{2}$. Factors of production are fully utilised and their endowments are given exogenously. However, the stock of capital of type 1 can increase by an inflow of foreign capital. Production functions exhibit constant returns to scale with diminishing marginal productivity to each factor.

The following symbols will be used in the equations:

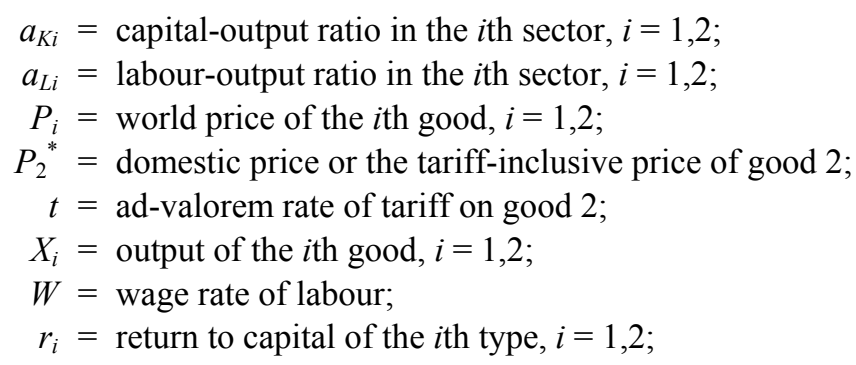

${ }^{1}$ The new seed-fertiliser technology, commonly known as the Green Revolution, which was adopted in several developing countries including India a few decades ago, is of this type. 
$L^{*}=$ fixed amount of supply of labour;

$K_{i}^{*}=$ fixed stock of capital of the $i$ th type, $i=1,2$;

$A=$ state of technology in the production of good 1;

$\wedge=$ proportional change.

A general equilibrium of the system is represented by the following set of equations:

$$
\begin{array}{cccccc}
W \cdot a_{L 1}+r_{1} \cdot a_{K 1}=P_{1} & \ldots & \ldots & \ldots & \ldots & \ldots \\
W \cdot a_{L 2}+r_{2} \cdot a_{K 2}=P_{2}^{*} & \ldots & \ldots & \ldots & \ldots & \ldots \\
a_{L 1}=a_{L 1}\left(W / r_{1}, A\left(K_{1}^{*}\right)\right) & \ldots & \ldots & \ldots & \ldots & \ldots \\
(-) \quad(-)(+) & & & & & \\
a_{K 1} \cdot X_{1}=K_{1}^{*} & \ldots & \ldots & \ldots & \ldots & \ldots \\
a_{K 2} \cdot X_{2}=K_{2}^{*} & \ldots & \ldots & \ldots & \ldots & \ldots \\
a_{L 1} \cdot X_{1}+a_{L 2} \cdot X_{2}=L^{*} & \ldots & \ldots & \ldots & \ldots & \ldots
\end{array}
$$

Equation (3) states that the labour-output ratio is a decreasing function of both the wage-rental ratio in sector 1 as well as the state of technology while the latter is a positive function of the capital stock of type 1 . As $K_{1}^{*}$ increases due to an inflow of foreign capital, it ushers in a more labour-saving technical progress, which lowers the labouroutput ratio $a_{L 1}$ in that sector. However, it does not affect the capital-output ratio $a_{K 1}$.

We should note that the production structure described by (1) - (6) depicts an indecomposable system. So input prices are not determined by product prices alone. Equations (1) and (2) describe a competitive equilibrium, whereas Equations (4) - (6) are the full-employment conditions. Given $K_{1}^{*}$ there are five equations (namely, Equations (1) - (2) and (4) - (5)) to solve for five unknowns $\left(W, r_{1}, r_{2}, X_{1}\right.$, and $\left.X_{2}\right)$. Once we know the factor prices, for given $K_{1}^{*}$, all the factor coefficients are also known.

Before going to comparative statics, it is important to mention that our measure of welfare in this small open economy is national income at international prices, $Y$, and it is expressed as follows.

$$
Y=W \cdot L^{*}++r_{2} \cdot K^{*}-t \cdot P_{2} \cdot X_{2} \quad \ldots \quad \ldots \quad \ldots \quad \ldots
$$

Here without the loss of any generality, we assume that the entire stock of capital of type 1 is foreign-owned and its return is fully repatriated.

\subsection{The Effects of an Increase in $K_{1}^{*}$}

Owing to an inflow of foreign capital, the stock of foreign capital in the economy $K_{1}^{*}$ goes up. We are interested to find out the effects of such an inflow on 
the factor prices and the levels of production of the two sectors. Using (4) and (5), Equation (6) can be rewritten as

$$
\left(a_{L 1} / a_{K 1}\right) \cdot K_{1}^{*}+\left(a_{L 2} / a_{K 2}\right) \cdot K_{2}^{*}=L^{*} \quad \ldots \quad \ldots \quad \ldots \quad \ldots
$$

We should note that in this model the three factor prices, $W, r_{1}$ and $r_{2}$, are determined by solving Equations (1), (2), and (6.1) simultaneously. Now taking total derivatives of these three equations we respectively, get $^{2}$

$$
\begin{aligned}
& \theta_{L 1} \cdot \hat{W}+\theta_{K 1} \hat{r}_{1}=-\left(\partial a_{L 1} / \partial A\right) \cdot A^{\prime} \cdot\left(W / P_{1}\right) \cdot d K_{1}^{*} \quad \ldots \quad \ldots
\end{aligned}
$$

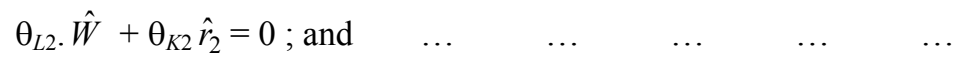

$$
\begin{aligned}
& \left(\sigma_{1} \cdot \lambda_{L 1}+\sigma_{2} \cdot \lambda_{L 2}\right) \cdot \hat{W}-\sigma_{1} \cdot \lambda_{L 1} \hat{r}_{1}-\sigma_{2} \cdot \lambda_{L 2} \hat{r}_{2}=\left(d K_{1}^{*} / L^{*}\right) \cdot\left[\left(a_{L 1} / a_{K 1}\right)+\right. \\
& \begin{array}{lllllll}
\left.\left(K_{1} * / a_{K 1}\right) \cdot\left(\partial a_{L 1} / \partial A\right) \cdot A^{\prime}\right] & \ldots & \ldots & \ldots & \ldots & \ldots
\end{array}
\end{aligned}
$$

where $\lambda_{L 1}=\left(a_{L 1}, X_{1} / L^{*}\right) ; \lambda_{L 2}=\left(a_{L 2} . X_{2} / L^{*}\right) ; \theta_{i j}=$ share of the $i$ th input in the $j$ th industry for $i=L, K ; j=1,2 ; \sigma_{j}=\left[\left(d\left(a_{K j} / a_{L j}\right) / d\left(W / r_{j}\right)\right) .\left(\left(W / r_{j}\right) /\left(a_{K j} / a_{L j}\right)\right)\right]$ is the elasticity of substitution between capital and labour in the $j$ th industry and the circum flex denotes a proportional change.

Using Cramer's rule from (1.1), (2.1), and (6.2) we can solve ${ }^{3}$

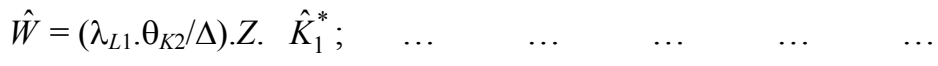

$$
\begin{aligned}
& \hat{r}_{2}=-\left(\lambda_{L 1} \cdot \theta_{L 2} / \Delta\right) . Z . \quad \hat{K}_{1}^{*} \text {; and, } \quad \ldots \quad \ldots . \quad \ldots \quad \ldots \\
& \hat{r}_{1}=-\left(\theta_{L 1} \cdot \theta_{K 2} / \Delta\right) \cdot\left[\lambda_{L 1}+E \cdot\left\{\lambda_{L 1} \cdot\left(1+\sigma_{1}\right)+\lambda_{L 2} \cdot\left(\sigma_{2} / \theta_{K 2}\right)\right\}\right] \cdot \hat{K}_{1}^{*} \quad \ldots
\end{aligned}
$$

where, $\Delta=\left\{\theta_{L 1} \cdot \theta_{K 2} \cdot \sigma_{1} \cdot\left(a_{L 1} / a_{K 1}\right) \cdot K_{1}^{*}+\theta_{K 1} \cdot\left[\theta_{L 2} \cdot \sigma_{2} \cdot K_{2}^{*}+\theta_{K 2} \cdot\left(\sigma_{1} \cdot K_{1}^{*} \cdot\left(a_{L 1} / a_{K 1}\right)+\right.\right.\right.$

$$
\begin{gathered}
\left.\left.\left.\sigma_{2} . K_{2}^{*}\right)\right]\right\}>0 ; \\
\mathrm{Z}=\left[\theta_{K 1}+E \cdot\left(\theta_{K 1}-\theta_{L 1} \cdot \sigma_{1}\right)\right] ;
\end{gathered}
$$

and, $E=\left\{\left(\partial a_{L 1} / \partial A\right) \cdot A^{\prime} .\left(K_{1}^{*} / a_{L 1}\right)\right\}$ is the elasticity of the labour-output ratio in the export sector with respect to the size of foreign capital stock and $E<0$ since $\left(\partial a_{L 1} / \partial A\right)<0$.

From $(8.1-8.2)$ it follows that $\hat{W}<0$ and $\hat{r}_{2}>0$ iff

$$
Z=\left[\theta_{K 1}+E .\left(\theta_{K 1}-\theta_{L 1}, \sigma_{1}\right)\right]<0 \quad \ldots \quad \ldots \quad \ldots \quad \ldots \quad \ldots
$$

From (9) one can observe that if (i) $\sigma_{1}$ is sufficiently low and (ii) $E$ is sufficiently negative, then the condition may be satisfied.

\footnotetext{
${ }^{2}$ Equation (6.2) has been derived in Appendix I.
}

${ }^{3}$ See Appendix II for detailed derivation. 
Now from (5) one can derive

$$
\begin{aligned}
\hat{X}_{2} & =-\hat{a}_{K 2} \quad \text { (since } K_{2}^{*} \text { does not change) } \\
\text { or, } \hat{X}_{2} & =\theta_{L 2} \cdot \sigma_{2} \cdot\left(\hat{r}_{2}-\hat{W}\right)
\end{aligned}
$$

Using (8) this becomes

$$
\hat{X}_{2}=-\left(\theta_{L 2} \cdot \sigma_{2} / \Delta\right) \cdot Z \cdot \lambda_{L 1} \cdot \hat{K}_{1}^{*}>0 \text { iff } Z<0 . \quad \ldots \quad \ldots \quad \ldots \quad \ldots
$$

Now from (7)

$$
\left(d Y / d K_{1}^{*}\right)=\underset{(-)}{\left(d W / d K_{1}^{*}\right) \cdot L^{*}+\left(d r_{2} / d K_{1}^{*}\right) \cdot K_{2}^{*}-t \cdot P_{2} \cdot\left(d X_{2} / d K_{1}^{*}\right)} \ldots
$$

\section{$(+)$}

Using (8) and (10), (7.1) can be reduced to ${ }^{4}$

$$
\left(d Y / d K_{1}^{*}\right)=\left(\lambda_{L 1} \cdot L^{*} \cdot W / K_{1}^{*} \cdot \Delta\right) \cdot\left[\lambda_{L 1} \cdot \theta_{K 2}+\lambda_{L 2} \cdot t \cdot \sigma_{2}\right] \cdot Z \quad \ldots \quad \ldots \quad \ldots
$$

From (7.2) it is evident that

$$
\left(d Y / d K_{1}^{*}\right)<0 \text { iff } Z<0 .
$$

Thus, an inflow of foreign capital into the export sector of the economy is immiserising if and only if condition (9) is satisfied.

The intuition behind this result is quite clear. The key issue is whether the output of the protected import-competing sector rises or not. Since the importcompeting sector is not affected directly due to an inflow of foreign capital, everything hinges on the direction of movement of the export sector's labour demand schedule. On the one hand, the foreign capital inflow tends to increase labour demand by the export sector; and on the other, the labour-saving technology transfer tends to reduce it. When condition (9) is satisfied, the second effect dominates. As a consequence, $W$ falls and $r_{2}$ increases. Producers in sector 2 will adopt a more labour-intensive technique of production. Hence, the capital-output ratio of the tariff-protected import-competing sector, $\mathrm{a}_{K 2}$, falls and the output, $X_{2}$, increases since capital of type 2 is fully utilised. The economy's welfare measured by national income at world prices decreases if the increased cost of tariff-protection (as $X_{2}$ increases) outweighs the increase in domestic factor incomes. This happens if condition (9) is satisfied.

\section{CONCLUDING REMARKS}

The standard result in the theory of trade is that an inflow of foreign capital into the protected import-competing sector of a small open economy with full repatriation of foreign capital income leads to a fall in the welfare of the economy.

${ }^{4}$ This has been derived in Appendix III. 
This is known as the famous 'immiserising' result of foreign capital inflow. Beladi and Marjit (1992) have generalised this result by showing that one may get the immiserising effects of foreign capital inflow even if the foreign capital flows into the export sector of the economy. However, Jones and Marjit (1992) have pointed out that to show the immiserising result in the latter case in a full-employment framework, one requires at least a three-sector model. In a two-sector, fullemployment model it is not possible to show that growth in the foreign capital employed in the export sector of a small open economy will lead to such a result. In this short paper, I have shown that we may get the immiserising result even in this framework if the inflow of foreign capital into the export sector is accompanied by technology transfer, and that it leads to a fall in the labour-output ratio in this sector. However, the rate of fall in the labour-output ratio must be such that the wage rate of labour (the inter-sectoral mobile factor) falls due to an increase in foreign capital inflow. If the wage rate falls, the rental rate on domestic capital engaged in the import-competing sector will rise, leading to a fall in the capital-output ratio in this sector. Full-employment of domestic capital leads to an expansion of the importcompeting sector of the economy and, thus, the welfare of the economy may fall through an increased distortionary effect due to tariff protection.

\section{Appendices}

\section{APPENDIX I}

Differentiating Equation (6.1) and after putting $d K_{2}{ }^{*}=d L^{*}=0$, we get

$$
\begin{aligned}
& \left(a_{L 1} / a_{K 1}\right) \cdot d K_{1}{ }^{*}+K_{1}{ }^{*} \cdot\left[\left\{a_{K 1} \cdot\left(\partial a_{L 1} / \partial\left(W / r_{1}\right)\right) \cdot d\left(W / r_{1}\right)+\left(\partial a_{L 1} / \partial A\right) \cdot A^{\prime} \cdot d K_{1}{ }^{*}\right)-\right. \\
& \left.\left.\quad a_{L 1} \cdot d a_{K 1}\right\} /\left(a_{K 1}\right)^{2}\right]-\sigma_{2} \cdot\left(\hat{W}-\hat{r}_{2}\right) \cdot\left(a_{L 2} / a_{K 2}\right) \cdot K_{2}{ }^{*}=0 \\
& \text { or, } K_{1}{ }^{*} \cdot \sigma_{1}\left(\hat{W}-\hat{r}_{1}\right) \cdot\left(a_{L 1} / a_{K 1}\right)+\sigma_{2}\left(\hat{W}-\hat{r}_{2}\right)\left(a_{L 2} / a_{K 2}\right) \cdot K_{2}{ }^{*}=d K_{1}{ }^{*} \cdot\left[\left(a_{L 1} / a_{K 1}\right)+\right. \\
& \left.\quad\left(\partial a_{L 1} / \partial A\right) A^{\prime} \cdot\left(K_{1}{ }^{*} / a_{K 1}\right)\right] \\
& \text { or, } \sigma_{1} \cdot\left(\hat{W}-\hat{r}_{1}\right) \cdot a_{L 1} X_{1}+\sigma_{2}\left(\hat{W}-\hat{r}_{2}\right) \cdot a_{L 2} \cdot X_{2}=\left(d K_{1}{ }^{*} / a_{K 1}\right) \cdot\left[a_{L 1}+K_{1}{ }^{*} \cdot\left(\partial a_{L 1} / \partial A\right) \cdot A^{\prime}\right]
\end{aligned}
$$

(obtained after using Equations (4) and (5))

$$
\begin{aligned}
& \text { or, } \sigma_{1} \cdot \lambda_{L 1} \cdot\left(\hat{W}-\hat{r}_{1}\right)+\sigma_{2} \lambda_{L 2}\left(\hat{W}-\hat{r}_{2}\right)=\left(d K_{1}{ }^{*} / a_{K 1} \cdot L^{*}\right)\left[a_{L 1}+K_{1}{ }^{*} \cdot\left(\partial a_{L 1} / \partial A\right) \cdot A^{\prime}\right] \\
& \text { or, } \hat{W} \cdot\left(\sigma_{1} \lambda_{L 1}+\sigma_{2} \lambda_{L 2}\right)-\hat{r}_{1} \sigma_{1} \cdot \lambda_{L 1}-\hat{r}_{2} \sigma_{2} \cdot \lambda_{L 2}=\left(d K_{1}^{*} / L^{*}\right) \cdot\left[\left(a_{L 1} / a_{K 1}\right)+\right. \\
& \left.\left(\partial a_{L 1} / \partial A\right) A^{\prime} .\left(K_{1}^{*} / a_{K 1}\right)\right] \quad \ldots \quad \ldots \quad \ldots \quad \ldots \quad \ldots
\end{aligned}
$$




\section{APPENDIX II}

We write (1.1), (2.1), and (6.2) in the matrix form as follows.

$$
\left(\begin{array}{lcc}
\theta_{L 1} & \theta_{K 1} & 0 \\
\theta_{L 2} & 0 & \theta_{K 2} \\
\left(\sigma_{1} \lambda_{L 1}+\sigma_{2} \lambda_{L 2}\right) & -\sigma_{1} \lambda_{L 1} & -\sigma_{2} \lambda_{L 2}
\end{array}\right)\left(\begin{array}{l}
\hat{W} \\
\hat{r}_{1} \\
\hat{r}_{2}
\end{array}\right)=\left(\begin{array}{c}
-\left(\partial a_{L 1} / \partial A\right) A^{\prime} \cdot\left(W / P_{1}\right) d K_{1}^{*} \\
0 \\
\left\{\left(a_{L 1} / a_{K 1}\right)+\left(K_{1}^{*} a_{K 1}\right)\left(\partial a_{L 1} / \partial A\right) \cdot A^{\prime}\right\}
\end{array}\right)
$$

Here, $\Delta=\theta_{L 1} \theta_{K 2} \sigma_{1} \lambda_{L 1}+\theta_{K 1} .\left[\theta_{L 2} \sigma_{2} \lambda_{L 2}+\theta_{K 2}\left(\sigma_{1} \lambda_{L 1}+\sigma_{2} \lambda_{L 2}\right)\right]$

Using (4) it becomes

$\Delta=\left\{\theta_{L 1} \theta_{K 2} \sigma_{1}\left(a_{L 1} / a_{K 1}\right) K_{1}^{*}+\theta_{K 1}\left[\left[\theta_{L 2} \sigma_{2} K_{2}^{*}+\theta_{K 2} \cdot\left(\sigma_{1} K_{1}^{*} \cdot\left(a_{L 1} / a_{K 1}\right)+\sigma_{2} K_{2}^{*}\right)\right]\right\}>0\right.$.

Solving (A.1) by Cramer's rule we get

$$
\begin{aligned}
& \hat{W}=(1 / \Delta)\left[-\left(\left(\partial a_{L 1} / \partial A\right) A^{\prime} .\left(W / P_{1}\right)\right) \cdot \theta_{K 2} \sigma_{1} \lambda_{L 1} d K_{1}^{*}\right. \\
& \left.+\theta_{K 1} \cdot \theta_{K 2} \cdot\left\{\left(a_{L 1} / a_{K 1}\right)+\left(K_{1}^{*} / a_{K 1}\right) \cdot\left(\partial a_{L 1} / \partial A\right) \cdot A^{\prime}\right\}\left(d K_{1}^{*} / L^{*}\right)\right] \\
& =(1 / \Delta)\left[E \cdot\left\{\left(\theta_{L 1} \sigma_{1} \lambda_{L 1} / K_{1}^{*}\right)+\left(\theta_{K 1} a_{L 1} / L^{*} \cdot a_{K 1}\right)\right] \cdot \theta_{K 2} \cdot d K_{1}^{*}\right. \\
& =\left(\theta_{K 2} d K_{1}^{*} / \Delta\right)\left[E .\left\{\left(\theta_{K 1} \lambda_{L 1} / K_{1}^{*}\right)-\left(\theta_{L 1} \sigma_{1} \lambda_{L 1} / K_{1}^{*}\right)\right\}+\left(\theta_{K 1} \lambda_{L 1} / K_{1}^{*}\right)\right] \\
& =\left(\lambda_{L 1} \theta_{K 2}\right) \cdot Z \cdot \hat{K}_{1}^{*} \quad \ldots \quad \ldots \quad \ldots \quad \ldots \quad \ldots \quad \ldots \\
& \hat{r}_{2}=(1 / \Delta)\left[-\theta_{K 1} \theta_{L 2}\left\{\left(a_{L 1} / a_{K 1}\right)+\left(K_{1}^{*} / a_{K 1}\right) \cdot\left(\partial a_{L 1} / \partial A\right) \cdot A^{\prime}\right\} \cdot\left(d K_{1}^{*} / L^{*}\right)\right. \\
& \left.+\left(\partial a_{L 1} / \partial A\right) A^{\prime}\left(W / P_{1}\right) \cdot \theta_{L 2} \cdot \sigma_{1} \lambda_{L 1} \cdot d K_{1}^{*}\right] \\
& =(1 / \Delta)\left[-\left(\theta_{K 1} / L^{*}\right)\left(a_{L 1} / a_{K 1}\right) \cdot\left\{1+\left(\partial a_{L 1} / \partial A\right) \cdot\left(A^{\prime} / a_{L 1}\right) \cdot K_{1}^{*}\right\}\right. \\
& \left.+\left(a_{L 1} \cdot W / P_{1} K_{1}^{*}\right) \cdot \sigma_{1} \cdot \lambda_{L 1} \cdot\left\{\left(\partial a_{L 1} / \partial A\right) \cdot\left(A^{\prime} \cdot K_{1}^{*} / a_{L 1}\right)\right\}\right] \cdot \theta_{L 2} d K_{1}^{*} \\
& =\left(\theta_{L 2} \cdot d K_{1}^{*} / \Delta\right)\left[-\left(\theta_{K 1} \cdot a_{L 1} X_{1} / L^{*} \cdot K_{1}^{*}\right) \cdot\{1+E\}+\left(\theta_{L 1} \sigma_{1} \lambda_{L 1} \cdot E / K_{1}^{*}\right)\right] \\
& =\left(\theta_{L 2} \cdot \lambda_{L 1} \cdot \hat{K}_{1}^{*} / \Delta\right)\left[E \cdot\left(\theta_{L 1} \sigma_{1}-\theta_{K 1}\right)-\theta_{K 1}\right] \\
& =-\left(\theta_{L 2} \cdot \lambda_{L 1} . \hat{K}_{1}^{*} / \Delta\right)\left[\theta_{K 1}+E \cdot\left(\theta_{K 1}-\theta_{L 1} \sigma_{1}\right)\right]
\end{aligned}
$$

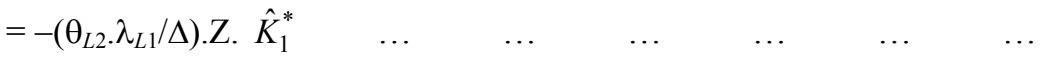

and,

$$
\begin{aligned}
\hat{r}_{1}=(1 / \Delta) \cdot\left[-\theta_{L 1} \theta_{K 2}\left\{\left(a_{L 1} / a_{K 1}\right)+\left(\partial a_{L 1} / \partial A\right) \cdot A^{\prime} \cdot\left(K_{1}^{*} / a_{K 1}\right)\right\}\left(d K_{1}^{*} / L^{*}\right)\right. \\
\left.-\left(\partial a_{L 1} / \partial A\right) \cdot A^{\prime} \cdot\left(W / P_{1}\right) \cdot d K_{1}^{*} \cdot\left\{\theta_{L 2} \sigma_{2} \lambda_{L 2}+\theta_{K 2} \cdot\left(\sigma_{1} \lambda_{L 1}+\sigma_{2} \lambda_{L 2}\right)\right\}\right]
\end{aligned}
$$




$$
\begin{aligned}
& =-\left(d K_{1}^{*} / \Delta\right) \cdot\left[\left(\theta_{L 1} \theta_{K 2} \cdot a_{L 1} / a_{K 1} \cdot L^{*}\right) \cdot(1+E)+E \cdot\left(W \cdot a_{L 1} / P_{1} K_{1}^{*}\right) \cdot\left\{\theta_{L 2} \cdot \sigma_{2} \cdot \lambda_{L 2}+\theta_{K 2} \cdot\left(\sigma_{1} \cdot \lambda_{L 1}+\right.\right.\right. \\
& \left.\left.\left.\sigma_{2} \lambda_{L 2}\right)\right\}\right] \\
& =-(1 / \Delta) \cdot \hat{K}_{1}^{*} \cdot\left[\theta_{L 1} \theta_{K 2} \lambda_{L 1} \cdot(1+E)+\theta_{L 1} E \cdot\left\{\theta_{L 2} \sigma_{2} \lambda_{L 2}+\theta_{K 2}\left(\sigma_{1} \cdot \lambda_{L 1}+\sigma_{2} \lambda_{L 2}\right)\right\}\right] \\
& =-\left(\hat{K}_{1}^{*} / \Delta\right) \cdot \theta_{L 1} \cdot\left[\theta_{K 2} \lambda_{L 1}+\text { E. }\left\{\theta_{K 2} \lambda_{L 1}+\theta_{L 2} \sigma_{2} \cdot \lambda_{L 2}+\theta_{K 2}\left(\sigma_{1} \lambda_{L 1}+\sigma_{2} \lambda_{L 2}\right)\right\}\right] \\
& =-\left(\theta_{L 1} \theta_{K 2} / \Delta\right)\left[\lambda_{L 1}+E\left\{\lambda_{L 1}\left(1+\sigma_{1}\right)+\lambda_{L 2}\left(\sigma_{2} / \theta_{K 2}\right)\right\}\right] . \hat{K}_{1}^{*}
\end{aligned}
$$

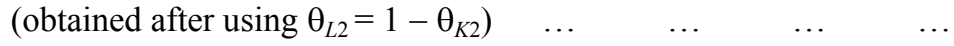

\section{APPENDIX III}

Using (8.1), (8.2), and (10) from (7.1) we may write

$$
\begin{aligned}
\left(d Y / d K_{1}^{*}\right)= & \left(\lambda_{L 1} / \Delta \cdot K_{1}^{*}\right) \cdot Z \cdot\left[L^{*} \cdot \theta_{K 2} \cdot W-\theta_{L 2} \cdot r_{2} \cdot K_{2}^{*}+t \cdot P_{2} \cdot \theta_{L 2} \cdot \sigma_{2} \cdot X_{2}\right] \\
= & \left(\lambda_{L 1} \cdot L^{*} \cdot W / \Delta \cdot K_{1}^{*}\right) \cdot Z \cdot\left[\theta_{K 2}+\lambda_{L 2} \cdot\left(t \cdot \sigma_{2}-\theta_{K 2}\right)\right] \\
= & \left(\lambda_{L 1} \cdot L^{*} \cdot W / \Delta \cdot K_{1}^{*}\right) \cdot Z \cdot\left[\theta_{K 2} \cdot\left(1-\lambda_{L 2}\right)+\lambda_{L 2} \cdot t \cdot \sigma_{2}\right] \\
= & \left(\lambda_{L 1} \cdot L^{*} \cdot W / \Delta \cdot K_{1}^{*}\right) \cdot Z \cdot\left[\lambda_{L 1} \cdot \theta_{K 2}+\lambda_{L 2} \cdot t \cdot \sigma_{2}\right] \\
& <0 \text { iff } Z<0 .
\end{aligned}
$$

\section{REFERENCES}

Beladi, H., and S. Marjit (1992) Foreign Capital and Protectionism. Canadian Journal of Economics 25, 233-38.

Beladi, H., and S. Marjit (1992a) Foreign Capital, Unemployment and National Welfare. Japan and the World Economy 4, 311-17.

Brecher, R. A., and C. F. Diaz Alejandro (1977) Tariffs, Foreign Capital and Immiserising Growth. Journal of International Economics 7, 317-22.

Chandra, V., and M. A. Khan (1993) Foreign Investment in the Presence of Informal Sector. Economica 60, 79-103.

Grinols, E. L. (1991) Unemployment and Foreign Capital: The Relative Opportunity Cost of Domestic Labour and Welfare. Economica 57, 107-21.

Gupta, M. R. (1997) Foreign Capital and the Informal Sector: Comments on Chandra and Khan. Economica 64, 353-63.

Jones, R. W., and S. Marjit (1992) International Trade and Endogenous Production Structure. In W. Neufiend and R. Riezman (eds) Economic Theory and International Trade. Berlin: Springer-Verlog.

Khan, M. A. (1982) Tariffs, Foreign Capital and Immiserising Growth with Urban Unemployment and Specific Factors of Production. Journal of Development Economics 10, 245-56. 